\title{
Participación ciudadana como eje del desarrollo social
}

\section{Citizen participation as the axis of social development}

\author{
Lusmidia Alvarado \\ lusmialvarado@hotmail.com \\ Código ORCID: 0000-0002-2178-0291 \\ Universidad Pedagógica Experimental Libertador, Venezuela
}

RESUMEN

- Artículo recibido en abril 2019

- Arbitrado en mayo 2019

- Publicado en julio 2019

La presente investigación se planteó generar una aproximación teórica para la participación ciudadana de la comunidad de La Represa de El Guapo del municipio Páez, estado Miranda, Venezuela, como eje del desarrollo social. El enfoque asumido fue cualitativo, con base en el método fenomenológico, apoyado en la hermenéutica. Los datos se recabaron mediante la entrevista en profundidad y la observación participante; para ello se usó el guion de preguntas semi estructuradas y la guía de observación. Los informantes claves fueron cuatro miembros del consejo comunal. El principal hallazgo estuvo en que la participación ciudadana es un complejo sistema de interrelaciones con distintos momentos, los cuales están relacionados con las variadas influencias que ejerce la comunidad durante las actividades que se planifican y desarrollan en esta. Se recomendó que sus miembros reciban formación en el área rural para atender y responder a las necesidades y exigencias del entorno.

Palabras clave: participación ciudadana; desarrollo social; organización comunitaria

\begin{abstract}
The present investigation set out to generate a theoretical approach for citizen participation in the La Represa de El Guapo community in the Páez municipality, Miranda state, Venezuela, as the axis of social development. The assumed approach was qualitative, based on the phenomenological method, supported by hermeneutics. Data was collected through in-depth interview and participant observation; For this, the semi-structured questions script and the observation guide were used. The key informants were four members of the community council. The main finding was that citizen participation is a complex system of interrelationships with different moments, which are related to the various influences that the community exerts during the activities that are planned and developed in it. It was recommended that its members receive training in the rural area to meet and respond to the needs and demands of the environment.
\end{abstract}

Keywords: citizen participation; social development; community organization 


\section{INTRODUCGIÓN}

Considerando la perspectiva actual de Estado venezolano, se puede visualizar cómo algunas de las políticas públicas se encuentran enfocadas en la participación ciudadana como herramienta central para la construcción de una sociedad que aprenda a solucionar conflictos y tomar decisiones, siendo un actor protagónico en la gestión pública.

Ejemplo de ello es lo expresado desde el preámbulo de la Constitución de la República Bolivariana de Venezuela (1999) donde se esgrime la refundación de la República para establecer una sociedad democrática, participativa $\mathrm{y}$ protagónica. De igual forma destaca lo tipificado en el artículo 62 del referido texto constitucional, donde se declara que todos los ciudadanos tienen derecho a participar libremente en los asuntos públicos, de manera directa o por medio de sus representantes electos. Asimismo, se señala en el artículo 70 que los medios de participación y protagonismo ciudadano son parte del ejercicio soberano que se le atribuye como un derecho; entre estos se encuentran las elecciones de cargos públicos, la consulta popular, asamblea de ciudadanos, cooperativas, cajas de ahorro y empresas comunitarias (entre otras), así como cualquier forma asociativa guiada por valores de mutua cooperación y solidaridad.
No obstante, al presentar la participación ciudadana como un derecho constitucional, en el artículo 132 de la Carta Magna se establece este principio, paralelamente, como un deber fundamental en el que toda persona requiere cumplir con sus responsabilidades sociales y de participación solidaria en la vida política y comunitaria. Es decir, la participación ciudadana es un deber y un derecho, según lo tipificado en el texto constitucional.

Otro aspecto fundamental de participación ciudadana es evocado desde el Plan Nacional "Simón Bolívar" (2007-2013), el I Plan y II Plan Socialista de Desarrollo Económico y Social de la Nación (2013-2019), en estos documentos se evidencia la necesidad de garantizar la participación del pueblo de manera democrática y protagónica como vía de consolidación de su soberanía.

Para Velásquez (1986), la participación es un proceso social en el que distintas agrupaciones sociales intervienen directa o indirectamente en el desarrollo de la sociedad. Partiendo de esta afirmación, se puede señalar que en efecto, es un hecho social, por cuanto este fenómeno se ejecuta entre seres humanos de una manera racional y voluntaria, de hecho el hombre es un ser social por excelencia, necesita vivir en sociedad para lograr su pleno desarrollo. Requiere 
del apoyo y cooperación de sus semejantes para satisfacer necesidades comunes.

Existen diferentes contextos de participación, pero también se da el caso que en las comunidades se cuenta con personas relacionadas a estos contextos ya sea por familiaridad, afiliación política, por desempeño profesional, entre otros; es precisamente el involucramiento de todas estas personas lo que va a contribuir a la satisfacción de las necesidades comunes.

Cunill (1991) clasifica a la participación como: social, política, comunitaria, y ciudadana: a) social: es la que se da en razón de la pertenencia del individuo en asociaciones $\mathrm{u}$ organizaciones para la defensa de los intereses de sus integrantes, y el interlocutor principal no es el Estado sino otras instituciones sociales, tales como: eclesiásticas, clubes privados, deportivos, de pesca, de transporte, entre otras; b) política: tiene que ver con la pertenencia de los ciudadanos en las organizaciones formales $y$ mecanismos del sistema político: partidos, parlamentos, ayuntamientos, elecciones. Es una participación mediada por los mecanismos de la representación política; c) comunitaria: relación con el Estado, es solo gestiones de la comunidad para obtener recursos que solucionen problemas de su vida, lo que se espera es recibir apoyo asistencial; d) ciudadana: es aquella participación donde los ciudadanos se involucran de manera directa en acciones públicas, con una concepción amplia de lo político y una visión del espacio público como espacio de ciudadanos. Esta participación pone en contacto a los ciudadanos y al Estado, en la definición de las metas colectivas y las formas de alcanzarlas a través de la cual se establece una relación más estrecha entre la comunidad y las autoridades.

Por ser la participación ciudadana un hecho complejo como eje del desarrollo social, se han establecido normas o principios, presentes en los documentos legales que la fundamentan, para que orienten su ejecución de manera armónica entre los ciudadanos, por ello es necesario que estas normas llamadas también valores sean inculcadas $y$ practicadas dentro de toda organización social. Por ejemplo, la Ley Orgánica de Participación Ciudadana y Poder Popular (LOPCPP, 2009), en su artículo 5 establece los principios de dicha participación. Son estos: "soberanía popular, corresponsabilidad, comunicación, voluntariedad, transparencia, pluralidad, información, eficiencia, solidaridad, equidad, humanismo, igualdad, universalidad, protagonismo, tolerancia, gratuidad e igualdad de género" (s.n). Cada uno de ellos evidencia cómo debe ser vista. 
La participación ciudadana representa, según Cunill (1991), "un medio de fortalecimiento de la sociedad civil, implicando la transferencia a ésta, de funciones $o$ decisiones que habían permanecido tradicionalmente en manos del Estado o de la Administración Pública” (p. 38). Con base en esto, se hace necesaria la redefinición entre lo público y privado, en el sentido, de que se deben crear los medios para que los ciudadanos sustentados en sus decisiones puedan participar en la formulación de las políticas públicas, originándose en algunos casos modalidades como la autogestión y cogestión.

La participación cuenta con medios de participación que son definidos por la Ley Orgánica del Poder Público Municipal (2010) en su artículo 259 como “(...) aquellos a través de los cuales los ciudadanos y ciudadanas podrán, en forma individual o colectiva, manifestar su aprobación, rechazo, observaciones, propuestas, iniciativas, quejas, denuncias $y$, en general, para expresar su voluntad respecto a asuntos de interés colectivo" (s.n).

Estos medios de participación, según el artículo 259 de la ley citada, son:

Cabildos abiertos, Asambleas ciudadanas, Consultas públicas, Iniciativa popular, Presupuesto participativo, Control social, Referendos, Iniciativa legislativa, Medios de comunicación social alternativos,
Instancias de atención ciudadana, Autogestión, Cogestión y otras formas de participación en la vida política, económica, social y cultural del Municipio Instancias de atención ciudadana, cooperativas, cajas de ahorro, mutuales, empresas autogestionarias y cogestionarias $\mathrm{y}$ otras formas asociativas.

Estos medios de participación se aplican a todos los órganos, y puede ser a través de consultas públicas que representan los espacios de discusión e intercambio de opiniones con la ciudadanía ante proyectos de ordenanzas; control social, viene a ser la acción individual o colectiva de control de vigilancia de la gestión local; referendos son los mecanismos a través del cual la ciudadanía puede revocar un mandato puede ser consultivo o aprobatorio; y las instancias de atención ciudadana son las dependencias locales al servicio de los ciudadanos de acuerdo a la necesidad de cada municipio.

Para lograr la organización del ciudadano en mecanismos y medios de participación, el poder popular, dentro de sus comunidades, ha representado una vía alternativa que permea el incremento de su nivel de conciencia para afrontar los posibles escenarios que se presenten como producto de la búsqueda de soluciones a las necesidades e intereses detectados en sus diferentes 
contextos, mejorando así la calidad de vida, tanto en el ámbito individual como colectivo.

En el contexto de lo aquí planteado, la educación se constituye en un componente de gran preeminencia para espolear la participación de las comunidades organizadas del poder popular; dicho proceso constituye una vía a través de la cual se pueden lograr los conocimientos, instrumentos y la preparación para alcanzar el tan anhelado empoderamiento o desarrollo social.

Ahora bien, el tipo de educación requerida para el cumplimiento de este fin no puede suscitarse por la vía escolarizada, puesto que el ejercicio de la soberanía ciudadana a través de estos senderos, evoca a personas que ya han superado las edades de la educación sistematizada y, sumado a esto, generalmente tienen responsabilidades que no le permiten asistir a una institución de formación.

Desde esta perspectiva, los conocimientos y habilidades requeridos para tal fin requieren ser iniciados mediante la educación no escolarizada, siendo esta una modalidad educativa que más se aproxima a la exigencia de los cambios sociales en las comunidades, dejando a un lado la rigurosidad del sistema educativo institucional $y$ buscando más bien la concienciación del individuo a través del mejoramiento de la percepción de sí mismo, su entorno y las relaciones con los otros, con miras al logro del bien común.

La participación ciudadana (por ser una declaración constitucional) impregna todos los estratos sociales del país constituyendo un entramado en el ámbito social. Desde tal perspectiva, este conjunto de relaciones sociales representa el génesis en la conformación de varios grupos y subgrupos con características de comportamiento bien específico, los cuales están orientados hacia el alcance de objetivos, propósitos y metas signadas por pautas culturales cuyos valores y creencias les son propios.

Cada uno de estos aspectos se encuentra inmerso en una red socio-cultural que subyace ante una concepción global unificante que le brinda direccionalidad a dicho cuerpo social, bajo unos principios y propósitos integradores que caracterizan dicha agrupación y la constituyen en organización.

Un elemento importante que vale la pena destacar en lo concerniente a la participación ciudadana es: el conflicto. Dicho vocablo está asociado con términos como: problema, discordia, disonancia y divergencia; además pareciera tener su origen en la incompatibilidad de propósitos e intereses por parte de grupos y personas, concretándose cuando uno de éstos 
interfiere de manera deliberada con el logro de los objetivos de la otra parte. Esto genera una interferencia; es decir una obstrucción o impedimento que podría concretarse por medio de impedimentos, omisiones, interposición de obstáculos, bloqueos, trabas, frenos e inconvenientes.

Según se resume de Chiavenato (2005), el conflicto puede ocurrir entre dos o más partes, entre grupos, entre personas, como grupos, de manera que los involucrados en el mismo son corresponsables tanto en su generación como en la resolución del mismo. Son variados los aspectos que podrían abordarse en relación con el conflicto como factor influyente en la participación ciudadana, especialmente en estos tiempos de cambio $y$ transformación que caracterizan a Venezuela; no obstante, es indispensable destacar lo propuesto por Koontz y Weihrich (2004):

Existen muchas fuentes potenciales de conflicto. Las organizaciones de hoy se caracterizan por relaciones complejas y un alto grado de interdependencia de las tareas, lo que puede provocar fricciones. Además, es común que las metas de las partes sean incompatibles, especialmente cuando éstas deben competir por recursos limitados. A ello hay que añadir el hecho de que cada persona posee sus propios valores $\mathrm{y}$ percepciones...pero el conflicto también puede proceder de otras fuentes. Pueden surgir conflictos entre personas en puestos de línea y staff. El estilo autocrático de liderazgo de un superior puede provocar conflictos. Antecedentes educativos diferentes son fuentes potenciales de conflicto. Quizás la causa más mencionada sea la falta de comunicación. (p. 459)

Con lo antes expuesto se evidencia que la existencia de numerosos métodos o técnicas para resolver los conflictos, depende de la procedencia del conflicto, si es de responsabilidades laborales, relaciones de trabajo, el tipo de disputas, la participación de otros individuos, la receptividad de recepción de las quejas, esto genera que los conflictos no deben ser resueltos a través de un método específico sino que este varía según la problemática existente.

Con base en los planteamientos anteriores, resalta el hecho de que en las agrupaciones sociales u organizaciones, el conflicto representa un aspecto que les aqueja de forma general; sea cual fuere su base de constitución (de carácter lucrativo o no, religiosas, sociales, culturales, intelectuales, asociaciones profesionales, políticas, públicas o privadas), en mayor o menor grado, según sea su nivel de complejidad, todas las modalidades organizacionales, presentan situaciones 
conflictivas, las cuales deben aprender a manejarse pues, aunque en principio parezcan forzosas e inquietantes, con el devenir (si son manejadas asertivamente) pueden representar una importante fuente para el crecimiento o renovación organizacional, así como un aporte para el mejoramiento de lo existente y una vía que conduzca al desarrollo social.

En el caso de Venezuela, por ser la participación comunitaria un derecho y deber constitucional, es importante atender este tipo de situaciones, especialmente desde la academia, donde pueden brindarse herramientas de apoyo valiosas para la conformación de organizaciones de este tipo que se estructuren a favor de la solución de los problemas de la vida en sociedad, específicamente en cada comunidad. De igual forma, es necesario atender los cambios y transformaciones surgidas a partir de la práctica y generación de los conflictos organizacionales, los cuales brindan contribuciones a las herramientas dadas inicialmente por la ciencia a las comunidades, valorando así los aportes que surgen desde la realidad de cada espacio comunal.

Pero queda en suspenso un conjunto de aspectos involucrados en ese proceso (y no en los resultados) e incrementados con el pasar del tiempo, que permitan comprender los diversos discursos $y$ escenarios suscitados en todo este proceso de avance comunal, el cual es concebido por algunos como desarrollo social. Licha (2002) destaca que el desarrollo social viene a ser la contribución para la modernización de las comunidades en progreso, acentuando el liderazgo asumido por sus habitantes. Parafraseando al autor, es un proceso que consiente el perfeccionamiento gradual y continuo de fenómenos o situaciones para transitar de un momento a otro en busca del bienestar de la colectividad. Ahora bien, esto implica que el desarrollo engloba la idea de avance, mejora, prosperidad, progreso, perfeccionamiento y adelanto de los instrumentos utilizados por los individuos en equipo, de manera que puedan encarar y sobreponerse a los obstáculos e inconvenientes que se deben suprimir para que la trascienda la sociedad.

Por su parte García (2007) concibe al desarrollo social como un procedimiento que promueve el incremento $y$ transformación organizada que afecta a una comunidad para acrecentar el nivel de vida de sus miembros, requiriendo para tal fin de un conjunto de estructuras útiles y productivas que demandan un manejo de capacidades que las avivan, abarcando elementos de tipo económico, educativos, social, cultural y hasta políticos. Esta definición llama la atención pues plantea el desarrollo social como un proceso que 
va más allá del alcance de beneficios económicos en una población; más bien, representa como especie de una vía de crecimiento asistido, integral $y$ sistemático, protagonizado por miembros de la comunidad que participan activamente en la construcción e integración de un conjunto de acciones prácticas para la solución de situaciones desfavorecedoras o débiles del contexto común. Es decir, el énfasis no puede ejercerse solo desde el alcance de logros que circunden exclusivamente el ámbito económico, sino que la valoración y conocimiento del proceso integral y complejo que caracteriza este desarrollo es fundamental.

Es importante acotar que partiendo de esta concepción, el desarrollo social pudiera ser contextualizado como una condición dentro de una localidad desde la cual son satisfechas las insuficiencias, carestías o privaciones de sus ciudadanos de manera sistémica, racional, humana, cultural y natural. Desde este tejido surgen inquietudes investigativas en torno a cómo describen y comprenden las comunidades los procesos que permiten obtener los elementos de ejecución y avance en las problemáticas comunitarias para llegar a la solución, permitiendo la investigación intensa de sus situaciones, funciones $\mathbf{o}$ manifestaciones, desde la participación ciudadana, para el alcance del referido tipo de desarrollo.

En el caso que nos ocupa, la comunidad de La Represa de El Guapo ha sido protagonista desde el año 2008 hasta la presente fecha, de un conjunto de coconstrucciones sociales en cuanto a su organización para la activación de la participación comunitaria en pro de su desarrollo social. De hecho, parte del liderazgo comunitario ha sido cambiado o desplazado producto de la necesaria dinámica democrática de este tipo de procesos, así como de la continuidad voluntaria de participar o no de los ciudadanos en estos asuntos; no obstante, sean los líderes iniciales o los recién electos, o ambos como equipo, la organización comunitaria ha tenido que atender y responder nuevos contextos problemáticos producto de las necesidades y exigencias de su entorno, así como de los nuevos retos que se visualizan para el avance comunitario.

Pero, un elemento notorio en esta situación es que estos procesos que han surgido no han sido reflexionados, pensados, sistematizados, conocidos $y$ valorados, por los mismos miembros que lo protagonizan. Las dinámicas de interacción han surgido producto de la satisfacción de necesidades y la atención de exigencias propias del entorno vital, pero sin la razón, conciencia y conocimiento propia de la comprensión 
de lo acontecido y ejercido a diario, fundamentándose en una perspectiva científica que le apoye en la ordenación de las experiencias. Existe un desconocimiento de las relaciones sistémicas y estructurales propias de la participación ciudadana y el desarrollo social ejercidas por los miembros de la Comunidad de La Represa de El Guapo, lo cual puede dificultar una toma de decisiones y resolución de conflictos más consciente y enfocada, el abordaje de nuevos escenarios de participación y el avance orientado en el surgimiento de dinámicas propias o adquiridas desde una transferencia de principios teórico referenciales propias de la ontología y axiología del fenómeno.

Por ello cabe preguntarse: ¿Cuáles son las categorías subyacentes de la participación ciudadana como eje del desarrollo social en la Comunidad de La Represa de El Guapo?, ¿cómo es la gestión de la participación ciudadana como eje del desarrollo social en los miembros de la comunidad de La Represa de El Guapo? De allí que el objetivo general del presente estudio haya sido generar una aproximación teórica sobre la participación ciudadana como eje del desarrollo social en la comunidad de La Represa de El Guapo, Municipio Páez, Estado Bolivariano de Miranda.
La participación ciudadana como eje del desarrollo social

La participación y el desarrollo social no pueden darse en el vacío, requieren planes y una acción integradora que preste cohesión y dirección a los esfuerzos locales. La acción integradora y de cohesión debe ser aportada por el municipio, donde el desarrollo social toma fuerza y se vuelve relevante al estar involucrados y comprometidos actores que tienen y comparten un proyecto de desarrollo común en un territorio. Como menciona Valverde (1999), la propia definición de participación conlleva a destacar la presencia de diversos actores, la capacidad de éstos para la movilización y gestión de recursos que permitan el desarrollo local y, la existencia de un proyecto común desde el cual se promueve el desarrollo económico, social y cultural de ese espacio.

La participación ciudadana surge como una alternativa para la construcción del consenso social y como un medio para equilibrar el peso relativo que, producto de los vacíos de poder, se han venido creando en el sistema como consecuencia de la burocracia e ineficiencia institucional. Además, nace como una herramienta de empoderamiento de aquellos sectores perjudicados, en respuesta a la ineficacia y falta de representatividad de la sociedad política. 
La gestión local es un proceso social donde se administran y movilizan los recursos humanos, financieros $y$ materiales por parte de los ciudadanos de una localidad, para potencializar $y$ fomentar la iniciativa colectiva. Se interrelacionan actores, intereses $y$ procesos de negociación, abriendo así espacios de participación ciudadana. En este sentido, lo local es el espacio físico donde se establecen relaciones sociopolíticas que hacen posible prácticas colectivas para la solución de problemas dentro de un municipio.

El nuevo escenario del desarrollo lo constituye así el entorno local, con su núcleo básico: el municipio, la comunidad, y con su ente institucional: la municipalidad, actuando como aglutinador y coordinador de las diferentes manifestaciones y demandas que se den en el seno de la comunidad, a la cual, si bien la representa, no la agota.

\section{MÉTODO}

La presente investigación se enfocó en la perspectiva cualitativa, en virtud de que los métodos, técnicas e instrumentos, dan respuesta al objeto de estudio desde un enfoque descriptivo, comprensivo e interpretativo, en un contexto en el que se representan los hallazgos partiendo de una particular cosmovisión. Martínez (2004), la define como "un proceso mediante el cual se construye inductivamente la realidad" (p. 21). En este sentido, lo que plantea el autor, es que este tipo de estudio al proceder de lo social estudia los fenómenos analizando sus interrelaciones por medio de la descripción de los hechos para la construcción de conocimientos.

Este proceso incluye la aproximación integral de la fenoménica de estudio para describirla, analizarla, comprenderla e interpretarla con apoyo de la hermenéutica, estableciendo una relación dialógica entre el todo y las partes de manera holística.

Una de las particularidades de los estudios fenomenológicos se encuentra en el significado especial que se le atribuye a lo social -individual y la experiencia subjetiva, enfatizando en la manera que los sujetos experimentan su realidad; como refiere Martínez (2009) cada fenómeno debe ser tratado de manera única y ceñido por los acontecimientos y sucesos particulares del ámbito en el que se producen; esto es una conformación de la realidad encarada en la particular experiencia vivida. De acuerdo con Latorre (como se citó en Sandín, 2003), “...su propósito es la búsqueda de los significados que las personas otorgan a sus experiencias como miembros de las instituciones” (p. 152). 
Lo hasta aquí descrito muestra como desde la fenomenología se requiere una búsqueda profunda y sistemática en dirección a lo esbozado por cada sujeto, así como la correspondencia con el ámbito del que forma parte.

La esencia de la faena investigativa se centró en describir, comprender, reflexionar y explicar una realidad particular como una conciencia significativa que produce un conocimiento específico pero válido. Pero esto no queda allí pues dicho tratamiento de la información conduce a la necesaria interpretación de la misma en un momento histórico particular, utilizando procesos de comunicación caracterizados por la dialógica.

En resumen, la perspectiva epistémicametodológica del presente estudio se apoyó en el enfoque cualitativo partiendo del fenomenológico hermenéutico. Se usó como cimiento el diseño de investigación planteado por Spiegelberg (como se citó en Leal, 2005), en el cual se plantean un conjunto de fases para el desarrollo de la investigación: a) descripción del fenómeno a estudiar, sin omitir detalles; b) búsqueda de diversas representaciones tomando en cuenta los datos obtenidos por los sujetos clave de la entrevista y la visión del fenómeno de estudio por parte de agentes externos; c) estructuración de información utilizando matrices, las cuales fueron trianguladas detallando convergencias y divergencias del fenómeno para crear la construcción de significados; d) interpretación de los significados por medio de la comprensión de la realidad escrita.

En esta oportunidad se utilizaron como técnicas para la recolección de información, la observación participante y la entrevista. En este sentido, cabe precisar que el instrumento que permitió el uso de dicha técnica fue una guía de observación a través del cuaderno de anotaciones. Con ello se pudo realizar el registro de lo observado tanto en lo relacionado con las conductas de los informantes clave como del entorno de la comunidad abordada. De allí que la observación participante se constituyó en una técnica valiosa que junto al instrumento denominado guía de observación contribuyó en brindar respuestas a las interrogantes planteadas.

En este mismo orden de ideas, la otra técnica de investigación a la que se recurrió para la recolección de información fue la entrevista a profundidad, la cual según Taylor $y$ Bodgan (2000) busca:

(...) la comprensión de las perspectivas de los informantes sobre sus propias vidas y experiencias, que son expresadas en su mismo lenguaje. No es un intercambio de preguntas $\mathrm{y}$ respuestas guiado por un 
formulario, sino una conversación entre iguales, en un proceso que indica gradualmente cuáles preguntas formular y cómo hacerlas $\mathrm{y}$ por ende hacia dónde guiar la entrevista. (p. 35)

Dicha técnica permitió la comprensión del fenómeno por parte del investigador, siendo importante la creación de un clima de empatía y cierta confianza sobre lo que percibían los informantes clave en relación con sus experiencias y creencias.

Como apoyo a esta técnica se utilizó como instrumento un guión de preguntas semi estructuradas, de manera que se pudiera moderar la indagación sobre las unidades de análisis surgidas del estudio. Para ello se hizo uso de cinco premisas que facilitaran el diálogo, procurando las respuestas abiertas dadas por los informantes clave desde sus creencias y sentimientos.

También es importante considerar que el uso de las referidas técnicas e instrumentos de investigación se registró con apoyo de una grabadora y cámara fotográfica, de manera de que se puedan revisar las evidencias relacionadas con las opiniones de los sujetos de investigación.

Los sujetos de investigación o informantes claves elegidos para contribuir en el proceso de recolección de información de la presente investigación, representan un muestreo intencional de casos extremos pues dos de ellos están formados desde antes de la constitución del Consejo Comunal, siendo capacitados en los talleres desarrollados por Alvarado (2008) para la construcción del modelo de participación ciudadana en dicha comunidad; mientras que los otros dos informantes claves seleccionados forman parte del vigente Consejo Comunal pero no recibieron entrenamiento $\mathrm{u}$ orientación alguna por parte de la referida investigadora, por lo que su conocimiento del modelo de participación ciudadana es netamente referenciado por otros.

Uno de los aportes centrales de los cuatro sujetos de investigación seleccionados, fue que sus respuestas en la entrevista a profundidad que se les realizó de manera individual y en momentos diferentes; del análisis de las mismas surgió lo relacionado con las categorías y subcategorías necesarias para llegar a la teorización.

\section{RESULTADOS}

Lo proveniente surge del análisis de lo que dijeron los informantes claves durante la entrevista, el cual representó la génesis para la validez y fiabilidad hermenéutica, iniciada en el pensamiento y deliberación de los 
actores sociales involucrados. Algunas de las preguntas formuladas fueron las siguientes:

1. ¿Qué es para usted la participación ciudadana y cuáles son los aspectos claves que la conforman?

2. ¿Cómo se desarrolla la participación de los ciudadanos durante la puesta en práctica de los proyectos en la comunidad?

3. ¿Cómo es el proceso de participación ciudadana durante el desarrollo de actividades para la solución de problemas individuales y colectivos?

4. ¿Cuáles son los principios o valores que orientan la participación ciudadana en su comunidad?

5. ¿¿Qué es para usted el desarrollo social y cómo se alcanza?

6. ¿Cómo ha sido su experiencia durante la planificación, desarrollo y logro de un proyecto en la comunidad?

7. ¿ ¿Cómo definiría a la comunidad de La Represa de El Guapo y por qué?
Con base en las respuestas de los informantes se desarrolló el ordenamiento conceptual, el cual consiste en "...la organización (y a veces clasificación) de los datos de acuerdo con un conjunto selectivo y especificado de propiedades y sus dimensiones" (Strauss y Corbin, 2002, p. 17). Esto implicó la construcción de las categorías y subcategorías, a partir de esa particular manera de visualizar la fenoménica de estudio por parte de los informantes clave, otorgando un sentido relacional a lo expresado por cada uno de ellos, identificando la coincidencia y discrepancia de los contenidos emitidos durante la entrevista para generar unos conceptos clave o resúmenes conclusivos que conducen a la teorización. En el Cuadro 1 se presentan las categorías que emergieron por cada una de las preguntas formuladas:

Cuadro 1. Categorías y subcategorías de la investigación

\begin{tabular}{cl}
\hline \multicolumn{1}{c}{ Categoría } & \multicolumn{1}{c}{ Subcategoría } \\
\hline Participación Individual en un colectivo & Beneficio común \\
& Preocupación común \\
Claves de conformación & Solución de problemas \\
& Respeto \\
& Solidaridad \\
& Conciencia \\
& Comunicación \\
& Voluntad para contribuir \\
& Corresponsabilidad \\
& Convivencia \\
& Confianza \\
& Cuidar lo que se tiene \\
\hline
\end{tabular}


Organización

Momentos de la Participación Ciudadana

Solución de problemas individuales

Solución de problemas colectivos

Valores de participación ciudadana
Elección del Consejo Comunal

Decisiones en conjunto

Asamblea de Ciudadanos

Realización de talleres

Complicaciones

Igualdad de condiciones

Convocatoria ciudadana

Participación u opinión ciudadana

Conformación de equipos

Elaboración de Planificación

Modificación y mejora de proyectos

Dirección interna

Ejecución propia

Supervisión

Apatía y cansancio

Mengua la participación

Cierre de proyecto

Poca motivación

Visita al afectado

Consignación de documentos probatorios

Trámite ante organismos de estado

Búsqueda de respuesta

Convocatoria

Inquietud y alta motivación ciudadana

Asamblea

Discusión y presentación de problemas

Búsqueda de soluciones

Elaboración de proyectos

Creación de equipos de trabajo

Clarificación de funciones

Presentación de proyecto a ente gubernamental

Ejecución de actividades

Surgen inconvenientes

Finalización del proyecto
Respeto
Comunicación
Convivencia
Responsabilidad
Corresponsabilidad
Determinación
Tolerancia
Cooperación
Compromiso
Voluntad 


\begin{tabular}{|c|c|c|}
\hline Categoría & Subcategoría & \\
\hline Dilucidación de desarrollo social & $\begin{array}{l}\text { Expansión de conocimientos individuales } \\
\text { institucionales hacia la comunidad } \\
\text { Cambio y mejora conjunta } \\
\text { Salir de la pobreza }\end{array}$ & o \\
\hline Requerimientos & $\begin{array}{l}\text { Conocimiento individual del contexto social } \\
\text { Alianza con entes gubernamentales } \\
\text { Alianza con otras comunidades } \\
\text { Diligenciar proyectos } \\
\text { Participación ciudadana } \\
\text { Visión colectiva } \\
\text { Unidad } \\
\text { Diálogo } \\
\text { Planificación y Organización } \\
\text { Voluntad } \\
\text { Esfuerzo } \\
\text { Conciencia }\end{array}$ & \\
\hline Elementos que subyacen en la gestión social & $\begin{array}{l}\text { Acompañamiento } \\
\text { Intereses } \\
\text { Beneficios } \\
\text { Satisfacción } \\
\text { Trabajo en equipo } \\
\text { Preocupación } \\
\text { Intangible } \\
\text { Visión colectiva } \\
\text { Colaboración } \\
\text { Rendición de cuentas } \\
\text { Influencia política } \\
\text { Bienestar colectivo } \\
\text { Monitoreo de actividades } \\
\text { Organización }\end{array}$ & \\
\hline Nivel de valoración & Excelente & \\
\hline Características de la comunidad & $\begin{array}{l}\text { Interés por el bien común } \\
\text { Participativa } \\
\text { Identidad colectiva } \\
\text { Valoración comunal } \\
\text { Disposición para el aprendizaje } \\
\text { Prospectiva conjunta } \\
\text { Visión colectiva } \\
\text { Activa } \\
\text { Organizados } \\
\text { Perseverancia } \\
\text { Reconocimiento de logros }\end{array}$ & \\
\hline
\end{tabular}


Para hacer la construcción racional en relación con la participación ciudadana como eje para el desarrollo social, se hace necesario reflexionar, en principio, sobre los significados que emergieron en relación con la participación ciudadana y el desarrollo social.

La participación ciudadana, en esta construcción teórica, fue vista como un complejo sistema de interrelaciones cuya esencia es la cooperación, intervención y contribución de la ciudadanía y organizaciones comunales en asuntos públicos, bajo una organización establecida y con elementos clave que promuevan su desarrollo eficiente y eficaz. Desde esta perspectiva surgieron un conjunto de planteamientos importantes de explicar para su comprensión en el contexto real de la fenoménica abordada y como parte de esta producción argumentativa.

Uno de esos planteamientos es la cualidad de sentirse "ser parte de" dentro de un hecho de la participación ciudadana. Es ineludible y obligatoria esta condición, pues se relaciona directamente con la voluntad $y$ conciencia de cada individuo y organización comunitaria para contribuir, constituirse en parte de la esencia de algo, representa un propósito vital, existencial, fundamental para todo ser humano. De allí que estos dos elementos claves representan un cimiento para la participación ciudadana pero un reto enorme para los entes que desean promoverla pues más allá de estrategias, normativas o razonamientos, la voluntad y la conciencia constituyen un acto que solo el "yo" (visto como acto volitivo) puede precisar y direccionar para impulsar la disposición.

Otra clave fundamental para la conformación de la participación ciudadana es la corresponsabilidad. Concebida en otros escenarios como un valor, dentro de este contexto investigativo fue estimada como un elemento clave que permite alcanzar la cooperación de los miembros de una comunidad. Esta responsabilidad compartida trasciende al hecho de que la ciudadanía impute a los organismos gubernamentales los aspectos relacionados con la solución de problemas de interés público, o viceversa; el enfoque enfatiza una mirada ciudadana a los pares, promoviendo una perspectiva colectiva de las cosas pues si el beneficio es común, el trabajo o esfuerzo también debe serlo. Esto también implica un sentido de pertenencia que ya se abordó anteriormente con la necesidad de ser parte de. La corresponsabilidad trae consigo otros elementos claves subyacentes como la confianza, respeto, solidaridad, convivencia y cuidar las posesiones de toda índole.

La comunicación también representa un aspecto imprescindible para la 
conformación de la participación ciudadana. El desarrollo adecuado de este proceso es fundamental en todas las áreas de la vida humana, pero su esencia en la participación ciudadana radica en el hecho de que los miembros de la comunidad (organizados o de manera particular) y los representantes de los entes gubernamentales requieren asirse de esta herramienta para poder interrelacionarse, validar las diferentes posiciones y organizar esfuerzos para la solución de los problemas.

Esto condujo a otro aspecto importante que resalta en ese complejo sistema de interrelaciones que es la participación ciudadana: la organización. Siendo una herramienta de la administración constituida para el alcance de fines, propósitos, metas u objetivos, por medio de la gestión del talento humano, no puede quedarse por fuera de esta construcción, por ser una vía imprescindible de encauce para las diferentes y complejas situaciones que surgen en la participación ciudadana.

Lo abordado hasta aquí implicó una perspectiva muy particular de la participación ciudadana; pero un elemento más específico aún que no puede pasarse por alto es lo relacionado con la estructuración de los momentos que conforman la participación ciudadana. Estos se relacionan directamente con las variadas influencias que se ejerzan durante el proceso, así como con los diferentes momentos o tipos de actividad que se planifiquen $y$ desarrollen. Desde esta construcción teórica se consideró fundamental la experiencia desarrollada por los miembros de la comunidad de la Represa de El Guapo.

En este sentido, se valoraron los siguientes momentos en la participación ciudadana: a) convocatoria ciudadana; b) participación u opinión ciudadana; c) conformación de equipos; d) elaboración de planificación; e) modificación y mejora de proyectos; f) dirección interna; g) ejecución propia; h) supervisión; i) apatía y cansancio; j) mengua la participación; k) cierre de proyecto.

La conciencia de la existencia de dichos momentos, en primera instancia, representa una ganancia para la comunidad referida, pues al reconocer su presencia se pueden establecer los mecanismos para su abordaje $y$ superación. Además, reconocerlos como parte de la realidad los hace menos vulnerables ante el surgimiento de otros conflictos, pues ya han sido asumidos y se le puede brindar importancia a otros aspectos emergentes que si requiera mayor cuidado y atención. Es importante destacar que la conciencia de estos momentos de participación ciudadana 
denota parte de su meticulosa organización y el estilo de trabajo que les caracteriza, permitiendo promover otros procesos superiores.

No obstante, esta construcción teórica necesariamente tomó en cuenta lo relacionado con el hecho de que estos momentos de participación ciudadana son diferentes cuando se aborda la solución a un problema individual que en uno colectivo. Desde la experiencia de los actores sociales involucrados en este proceso, no es el mismo transcurso que se desarrolla cuando se atienden problemas particulares que comunitarios. En el primero hay poca motivación, mientras que en el segundo se eleva el entusiasmo, la inquietud y las ganas de contribuir.

Diversas son las causas que generan esta situación, pero el énfasis discursivo se encuentra en el hecho de que los momentos son diferentes pues en la solución de problemas individuales el contacto con organismos de estado es casi inmediato, mientras que en los problemas grupales existe un proceso previo y complejo en el que el protagonismo lo tienen los miembros de la comunidad, y el cierre generalmente está a cargo de los líderes comunales responsables de la ejecución y rendición de cuentas del proyecto.
Esto vislumbró parte de los valores sociales que se deben fomentar en los miembros de la comunidad de la Represa de El Guapo; pues, la apatía, el cansancio y la disminución en la participación son valores negativos que de continuar conllevarían al fracaso de los proyectos necesarios para el desarrollo social.

Ahora bien, el desarrollo social también fue atendido en la presente construcción teórica pues representa la supremacía de lo que se espera alcanzar, siendo la participación ciudadana un fundamento central, una parte importante, un cimiento para su consolidación. Desde este bastimento teórico el desarrollo social es una realidad compleja y sistémica que se construye en equipo a través de un conjunto de iniciativas locales que buscan trascender lo individual $\mathrm{y}$ abrazar lo colectivo; es la expansión hacia el progreso y la transformación comunitaria. Esta postura demanda un despliegue de potencialidades humanas y concertación de esfuerzos (ciudadanos, liderazgo comunal y organismos de estado), en búsqueda de un bienestar común e integral que parten de una visión colectiva $y$ concertada.

Resalta el hecho de cómo el desarrollo social contiene un conjunto de elementos que subyacen durante la gestión del mismo. La concertación de los actores sociales, por ejemplo, es uno 
de los aspectos más difíciles de precisar pues el mismo no solo requiere conseguir los líderes de influencia que contribuyan a la promoción, liderato, ejecución y supervisión del proceso hasta el logro de los objetivos sino que, más aún, necesitan ganar la voluntad de ellos y convenir sus esfuerzos, definir en principio sus roles y luego el del resto de los equipos de trabajo, promover la proactividad antes que la mera ejecución de obras.

Toda esta disertación, sobre el desarrollo social, aunque pareciera compleja, por la cantidad de elementos que subyacen en ella, tiene un punto o eje central que permite afianzar la totalidad de elementos descritos. Este es la participación ciudadana. La experiencia de la comunidad de la Represa de El Guapo fue una muestra fiel de ello, de manera que el énfasis para alcanzar el tan anhelado desarrollo social tiene su base en la promoción acertada de la participación ciudadana.
Aproximación teórica sobre la participación ciudadana como eje del desarrollo social en la comunidad de La Represa de El Guapo, municipio Páez, estado Bolivariano de Miranda

Es importante clarificar que la construcción no pretendió ser una verdad irrefutable, sino la representación de una realidad particular que pudiera ser una génesis para localidades con características similares, de manera que simboliza una contribución generada a partir de un proceso razonado y dialógico que permite evidenciar fácilmente un conjunto de lineamientos para la gestión de la participación ciudadana en el desarrollo social de los miembros de la comunidad de La Represa de El Guapo, municipio Autónomo Páez, estado Miranda.

En la Figura 1 se pueden visualizar claramente los lineamientos relacionados con la gestión de la participación ciudadana como eje central del desarrollo social. 


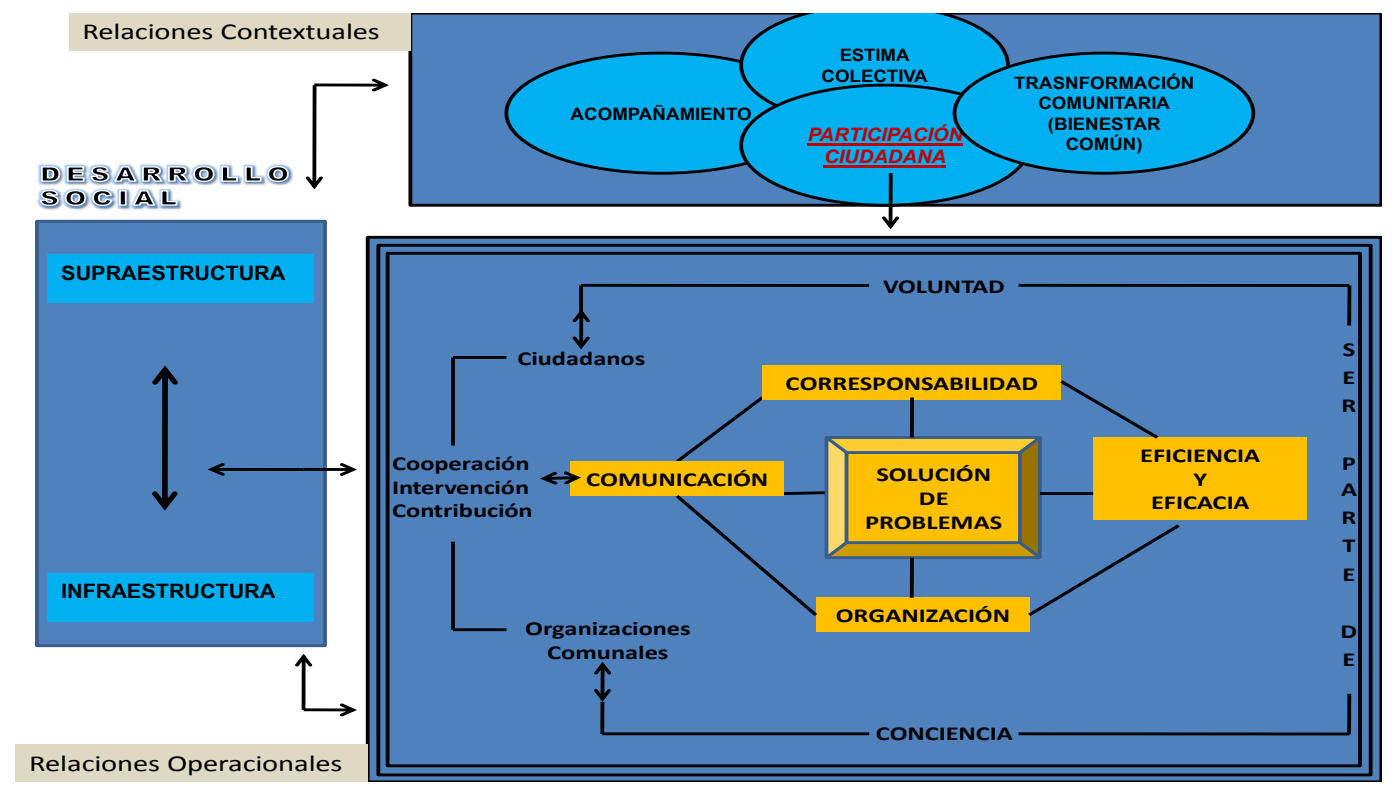

Figura 1. Aproximación teórica sobre la participación ciudadana como eje del desarrollo social en la comunidad de La Represa de El Guapo, municipio Autónomo Páez, estado Miranda

El desarrollo social presenta una supraestructura constituida por las relaciones contextuales que vienen a ser como especie del cuadro global o los ámbitos generales que surgen de la referida realidad compleja y sistémica. Ésta se compone principalmente de cuatro procesos (cuya estructuración interna conforma todo un abordaje necesario de indagar para su comprensión); estos son: a) acompañamiento; b) estima colectiva; c) transformación comunitaria (para el alcance de un bienestar común) y; d) participación ciudadana. El desarrollo de cada uno de estos procesos implicaría un estudio particular, como el que se realizó en esta oportunidad, razón por la cual el énfasis en esta ocasión es solo la participación ciudadana.

De igual manera ese mismo desarrollo social tiene una infraestructura, establecida desde la visión interna en cada uno de esos ámbitos. En ella se visualizan las relaciones operacionales del funcionamiento de ese fenómeno, la cual se construyó a partir del abordaje fenomenológico hermenéutico de la realidad de estudio descrita en el primer capítulo de este reporte de investigación, solo en lo relacionado con la participación ciudadana.

Las relaciones contextuales que generan la supraestructura del desarrollo social tienen una relación bidireccional con las relaciones operacionales de la participación ciudadana. Estas se interrelacionan y complementan, se nutren unas de otras para el logro de los objetivos propuestos dependiendo del proceso o sistema que se trabaje, de manera tal que no hay exclusión sino complementariedad entre ellas y deben 
relacionarse como un engranaje que añade valor en la optimización del fenómeno.

Ahora bien, desde esta perspectiva, la participación ciudadana presenta un conjunto de relaciones operacionales constituido por un complejo sistema de interrelaciones que la definen. Dicha participación se caracteriza por tres procesos básicos que se complementan entre sí como son la cooperación, contribución e intervención; estos aspectos son esencia misma para la participación y vienen a ser como especie de la puerta de entrada al sistema total. Los mismos son ejecutados por los ciudadanos de manera individual o por las organizaciones comunales que vienen a ser entes conformados por vecinos organizados estatutariamente. Se requiere de ambos sectores para el óptimo funcionamiento del sistema.

Dentro del mismo se desarrollan dos procesos en paralelo. El primero de ellos está conformado por tres procesos inmanentes al "yo" de los ciudadanos. Se refiere a la voluntad, conciencia y ser parte de. Cada uno de ellos es fundamental, pues permiten desarrollar la fuerza intangible del hacer que las cosas sucedan. Son el primer elemento que se debe trabajar para blindar la parte interna y más operativa del sistema total la cual, a su vez, representa el segundo proceso.
Consolidado y bajo una interrelación directa y compleja, se desarrolla este segundo proceso conformado por la comunicación, corresponsabilidad, organización, eficiencia y eficacia (vistos estos últimos como un todo). La comunicación representa la segunda puerta de entrada a este sistema interno; en virtud de la insistente manifestación e importancia que tanto autores como informantes clave le dieron a la misma, dicho proceso tiene un papel fundamental en todo el proceso. Viene a ser como especie de una puerta con bisagra que abre y cierra los espacios para avanzar.

Todas ellas conllevan una esencia fundamental, a un fin último y supremo de la participación ciudadana que viene a ser la pieza esencial, fortalecida y característica clave del Desarrollo Social: la solución de problemas. Esta representa un propósito clave en el marco de la participación ciudadana que inicia el génesis del desarrollo social. La solución de los problemas públicos es una necesidad permanente de la vida en comunidad; continuamente existen situaciones que deben ser resueltas, por lo que esta aproximación teórica constituye una perspectiva científica y consensuada de todo lo abordado.

Es importante mencionar que dicha representación gráfica fue presentada, compartida y discutida entre los 
miembros de la Comunidad de la Represa de El Guapo. Los informantes clave manifestaron claramente su acuerdo con tal estructuración $y$ declararon en diferentes momentos que se veían representados y comprendidos con esta construcción.

Esta aproximación teórica permitió visualizar los lineamientos de gestión, los cuales están estructurados en cada proceso planteado, así como en las interrelaciones de los mismos. En tal sentido, simboliza un hallazgo importante por cuanto se alcanzó comprender el fenómeno de estudio, se develaron los significados otorgados a cada elemento $y$ se brinda una contribución importante a la ciencia y la comunidad local abordada.

\section{CONCLUSIONES}

La participación ciudadana es vista como un complejo sistema de interrelaciones cuya esencia es la cooperación, intervención y contribución de la ciudadanía y organizaciones comunales en asuntos públicos, bajo una organización establecida y con elementos clave que promueven su desarrollo eficiente y eficaz.

También se pudo constatar a través de esta investigación que en la participación ciudadana se observan distintos momentos relacionados con las variadas influencias que se ejercen durante el proceso y las actividades que se planifiquen y desarrollen. En este sentido, se consideran importantes los siguientes momentos: a) convocatoria ciudadana; b) participación u opinión ciudadana; c) conformación de equipos; d) elaboración de planificación; e) modificación y mejora de proyectos; f) dirección interna; g) ejecución propia; h) supervisión; i) apatía y cansancio; j) mengua de la participación; k) cierre de proyecto. Estos momentos de participación ciudadana son diferentes cuando se aborda la solución a un problema individual o en uno colectivo, en el que el protagonismo lo tienen los miembros de la comunidad y el cierre generalmente está a cargo de los líderes comunales responsables de la ejecución y rendición de cuentas del proyecto.

Es oportuno destacar que existe la necesidad de fomentar valores sociales con la finalidad de mejorar la integración, contribuyendo así al logro de un desarrollo armónico. Entre estos valores se pueden mencionar, entre otros: el respeto, la corresponsabilidad, la tolerancia, cooperación, voluntariedad, compromiso, pluralidad y transparencia.

En lo referente al desarrollo social, en este se puede concebir la expansión hacia el progreso y la transformación comunitaria, lo cual demanda un despliegue de potencialidades humanas y concertación de esfuerzos (ciudadanos, 
liderazgo comunal y organismos de estado), en búsqueda de un bienestar común e integral que parten de una visión colectiva y concertada. El alcance del desarrollo social, implica el acuerdo en un conjunto de elementos que van desde la interiorización de realidades, pasando por la conceptualización de proyectos hasta el establecimiento de alianzas y consensos para el logro de un bienestar integral común.

Existen elementos que subyacen durante la gestión del desarrollo social, tales como la concertación de los actores sociales, el acompañamiento que permite orientar y reorientar actividades y procesos, monitorear (en cierto modo) a los ciudadanos y organizaciones y por último, la estima colectiva, la cual requiere de un trabajo sostenido $y$ concertado para definir, primeramente, una identidad de la comunidad o colectivo. Esto es importante por cuanto permite establecer los rasgos decisivos que caracterizan la localidad (ciudadanos, ambiente, cultura, economía, potencialidades, debilidades, entre otras) y precisados los mismos se puede hacer una introspección y prospectiva de la realidad, lo que facilita la generación de visiones en conjunto, en un mismo sentir, sin uniformidad pero con unidad.

Asimismo, se logró construir una aproximación teórica constituida por las relaciones contextuales que surgen de la referida realidad compleja y sistémica. Esta se compone principalmente de cuatro procesos: a) acompañamiento; b) estima colectiva; c) transformación comunitaria (para el alcance de un bienestar común) y; d) participación ciudadana.

\section{REFERENCIAS}

Alvarado, L. (2008). Modelo TeóricoPráctico derivado de la Participación Comunitaria en busca del Mejoramiento de la Calidad de Vida en la Comunidad de La Represa de EI Guapo. Caracas (tesis doctoral). Universidad Pedagógica Experimental Libertador, Instituto Pedagógico de Caracas, Venezuela

Constitución de la República Bolivariana de Venezuela (1999). Gaceta Oficial, 36.860 Extraordinario), Diciembre 30, 1999

Cunill, N. (1991). Participación Ciudadana dilemas y perspectivas para la democratización de los Estados Latinoamericanos. Caracas: Centro Latinoamericano de Administración para el Desarrollo

Chiavenato, I. (2005). Comportamiento Organizacional. México: Thomson

García, M. (2007). Perspectivas Teóricas en Desarrollo Local. España: Producción Editorial Gbiblo

Gómez, C. (1995). Métodos y Técnicas Cualitativas de Investigación en Ciencias Sociales. Madrid: Síntesis

Koontz, H y Weihrich, H. (2004). Administración. Una Perspectiva Global. México: Mc Graw-Hill

Ley Orgánica del Poder Público Municipal (2010). Gaceta Oficial de la 
República Bolivariana de Venezuela, 6015 (Extraordinaria), diciembre, 28, 2010

Ley Orgánica de Participación Ciudadana y Poder Popular (2009). Gaceta Oficial de la República Bolivariana de Venezuela, 39.335, junio, 28, 2009

Leal, J. (2005). La autonomía del sujeto investigador y la metodología de investigación. Mérida: Centro Editorial Litorama

Licha, I. (2002). Gerencia Social en América Latina: Enfoque y Experiencias Innovadoras. Washington D.C: Banco Interamericano de Desarrollo

Martínez, M. (2004). Escribir sin fallas: Manual Básico de Ortografía. España: Ediciones Nobel, S.A

Martínez, M. (2009). Ciencia y Arte en la Metodología Cualitativa. México: Editorial Trillas
Sandín, M. (2003). Investigación Cualitativa en Educación. Fundamentos y Tradiciones. España: Mc Graw Hill

Strauss, A. y Corbin, J. (2002). Bases de la Investigación Cualitativa. Técnicas y Procedimientos para desarrollar la teoría fundamentada. Colombia: Universidad de Antioquía

Taylor, S. y Bodgan, R. (2000). Introducción a los métodos cualitativos de investigación. (Tercera reimpresión). España: Paidós Básica

Valverde (1999). Participación para el desarrollo local. Cuaderno de Ciencias Sociales. FLACSO. No. 114. San José, Costa Rica

Velásquez, F. (1986).Crisis municipal y participación ciudadana en Colombia, Revista Foro, número 1, septiembre, 16-25 